FRBSF Working Paper 2002-07

\title{
Monetary Policy and the Slope Factor in Empirical Term Structure Estimations
}

\author{
Tao $\mathrm{Wu}^{*}$
}

First draft: March 10, 2001

This version: August 23, 2001

\begin{abstract}
This paper examines the empirical relationship between the movement of the slope factor in term structure of nominal interest rates and exogenous monetary- policy shocks in the U.S. after 1982. Using first a six-variable VAR model and then a GMM estimation model of the "Taylor rule", I estimate the exogenous monetary-policy shocks implied by each of them in the U.S. during this period. Meanwhile, a two-factor model is used to extract the underlying slope factor of the term structure. Results from the correlation study suggest that there is strong correlation between the slope factor and the exogenous monetary-policy shocks. Moreover, monetary-policy shocks can explain a large part of variability of the slope factor. This study provides strong evidence in support of Knez, Litterman and Scheinkman (1994)'s conjecture on the relation between the slope factor and the Federal Reserve policy, and is also consistent with the results in $\mathrm{Wu}$ (2001a)'s general-equilibrium based simulation study.
\end{abstract}

JEL Classification: C13, C22, E43, E44, E52, G12

${ }^{*}$ Special thanks go to Christopher Sims, Stefan Krieger, Hua He and my colleagues at Federal Reserve Bank of San Francisco for their insightful suggestions and comments. Email: tao.wu@sf.frb.org. Correspondence to: Tao Wu, Economic Research Department, Federal Reserve Bank of San Francisco, 101 Market Street, San Francisco, CA 94105. The views expressed herein are solely those of the author and not necessarily those of the Federal Reserve Bank of San Francisco or the Federal Reserve System. 


\section{Introduction}

The past two decades have seen a plethora of factor models of the term structure of interest rates. Following Vasicek (1977) and CIR(1985), numerous factor models have been developed and estimated, which use the unobservable latent factors to characterize certain aspects of the movement of the term structure, and are applied to the valuation of bonds and various interest rate options. A short list of the literature include Litterman and Scheinkman (1991), Longstaff and Schwartz (1992), Chen and Scott (1993), Duffie and Kan (1995), Dai and Singleton (1999), etc.

However, the best that the latent-factor models can do is to reveal the statistical pattern of the latent factors implied by the data, while little light is shed on the underlying structural sources of the movement of these factors. This is also reflected in the terminology by which the extracted factors are named. For example, Litterman and Scheinkman (1991) call their factors "level, "steepness" and "curvature". Dai and Singleton (1999) use the terms "level", "slope" and "butterfly", and many other empirical studies, based on the magnitude of the mean-reversion parameters of the latent factors, name them as "persistent", "less persistent" and "strong mean-reverting", etc. (for example, Chen and Scott (1993)). These labels describe how the latent factors influence the yield curve rather than indicating the underlying structural forces that drive the movement of these factors.

Understanding how the macroeconomic fundamentals are related to term structure factors is essential to comprehending the behavior of fixed-income securities, and is useful for valuation and arbitrage purposes. The latentfactor models use the dynamics of underlying latent factors to describe and formulate the expectation of the movement of instantaneous interest rates, while in reality the federal funds rates are determined based on the macroeconomic fundamentals by the Federal Reserve Board. Therefore, examining the structural sources of the latent factors and incorporating information about the fundamentals in making forecasts on the evolution of future term structure may bring an advantage to investment practitioners in exploiting the arbitrage opportunities on fixed-income security market and other financial markets.

A number of studies have addressed the question of the structural sources of latent factors. Knez, Litterman and Scheinkman (1994) perform a factor analysis of the money market returns in the U.S. from January 1985 to August 1988, and suspect the "steepness" factor that they find represents the 
impact of Federal Reserve policy on the yield curve. Evans and Marshall (1998) conduct a VAR study and find that the monetary policy shocks can explain a significant part of variability of slope of the yield curve, at least in short horizons. Wu (2001a) establishes a general-equilibrium based term structure model and shows that most of variability of the slope factor in his model is driven by exogenous monetary-policy shocks.

This study aims at exploring the empirical relationship between the movement of the slope factor and exogenous monetary-policy shocks in the U.S. after 1982. Unlike Evans and Marshall (1998), which simply regress the bond yields on a constant, bond maturity and maturity squared and take the coefficient of maturity as the slope of the yield curve, my study explicitly extracts the slope factor of the yield curve, using a two-factor Vasicek (1977) model. In order to extract the monetary-policy shocks, I adopt two different identification strategies through an identified Vector-autoregression (VAR) model as well as a Generalized Method of Moments (GMM) estimation model of the "Taylor rule". I then examine the relation between the slope factor and each of the two series of the monetary-policy shocks. The results from the two identification strategies are similar, which makes the paper's subsequent analysis more robust.

This paper is organized as follows. Section 2 lays out the estimation procedure of the two-factor term structure model. Section 3 discusses the setup of the VAR model and as well as the GMM estimation model of the "Taylor rule". Section 4 describes the data. Section 5 reports the estimation results and examines the implied relation between the slope factor and monetary policy shocks, and Section 6 concludes.

\section{A Two-factor Term Structure Model}

The term structure model used to extract the slope factor is a discretetime version of the models established in Vasicek (1977) and Babbs and Bowman (1999). I assume the state of the economy can be described by a two-dimensional vector of latent variables $F_{t}$, which follows a first-order VAR process:

$$
F_{t}=\mu_{F}+\Psi_{F} F_{t-1}+\Sigma_{F} u_{t}
$$

where $\Psi_{F}$ and $\Sigma_{F}$ are $2 \times 2$ matrices, and $u_{t}$ 's are $i . i . d$. white noises: $u_{t} \sim$ $N(0, I)$. 
The one-period short rate $r_{t}$ is assumed to be a linear function of the latent variables:

$$
r_{t}=\delta_{0}+\delta_{1}^{\prime} F_{t}
$$

I assume there is no arbitrage opportunity in the equilibrium. The nonarbitrage condition thus guarantees the existence of a risk-neutral measure $Q$ so that the price of any asset $P_{t}^{A}$ satisfies

$$
P_{t}^{A}=E_{t}^{Q}\left\{\exp \left(-r_{t}\right) P_{t+1}^{A}\right\}
$$

in which the expectation is taken under the measure $Q$. The Radon-Nikodym derivative $\zeta_{t+1}$ converts the risk-neutral measure to a data-generating measure, and for any random variable $Z_{t+1}$ the following equation is true:

$$
E_{t}^{Q}\left\{Z_{t+1}\right\}=E_{t}\left\{\zeta_{t+1} Z_{t+1}\right\} / Z_{t}
$$

As often in the no-arbitrage literature, $\zeta_{t+1}$ is assumed to follow a lognormal process:

$$
\zeta_{t+1}=\exp \left(-\frac{1}{2} \gamma^{\prime} \gamma-\gamma^{\prime} u_{t+1}\right)
$$

where $\gamma$ is the market price of risk associated with the source of uncertainty $u_{t}$. The nominal pricing kernel $m_{t+1}$ can thus be defined as

$$
m_{t+1}=\exp \left(-r_{t}\right) \zeta_{t+1}
$$

and can be used to price all the nominal assets in the economy:

$$
P_{t}^{A}=E_{t}\left\{m_{t+1} P_{t+1}^{A}\right\}
$$

If $b_{j, t}$ represents the price of a $j$-period nominal zero-coupon bond, then equation (2.7) implies:

$$
b_{j, t}=E_{t}\left\{m_{t+1} b_{j-1, t+1}\right\}
$$

Substituting (2.2), (2.6) into (2.8) we have

$$
b_{j, t}=E_{t}\left\{\exp \left(-\delta_{0}-\delta_{1}^{\prime} F_{t}-\frac{1}{2} \gamma^{\prime} \gamma-\gamma^{\prime} u_{t+1}\right) b_{j-1, t+1}\right\}
$$

Equations (2.1), (2.2) and (2.5) constitute a discrete-time Vasicek (1977) two-factor model. The logarithms of the bond prices in this model are affine 
functions of the latent variables $F_{t}$. More precisely, the formulae of the logarithm of the bond prices are given by

$$
\ln \left(b_{j, t}\right)=\bar{A}_{j}+\bar{B}_{j}^{\prime} F_{t}
$$

and the coefficients $\bar{A}_{j}$ and $\bar{B}_{j}$ are recursively defined by

$$
\begin{array}{rlr}
\bar{A}_{1} & =-\delta_{0} \\
\bar{B}_{1} & =-\delta_{1} \\
\bar{A}_{j+1}-\bar{A}_{j} & =\bar{B}_{j}^{\prime}\left(\mu_{F}-\Sigma_{F}^{\prime} \gamma\right)+\frac{1}{2} \bar{B}_{j}^{\prime} \Sigma_{F} \Sigma_{F}^{\prime} \bar{B}_{j}+\bar{A}_{1} \\
\bar{B}_{j+1} & =\Psi_{F}^{\prime} \bar{B}_{j}+\bar{B}_{1} ; \quad j=1,2, \ldots, J
\end{array}
$$

The continuously compounded yield to maturity $r_{j, t}$ of a $j$-period nominal zero-coupon bond is then given by

$$
r_{j, t}=-\ln \left(b_{j, t}\right) / j=A_{j}+B_{j} F_{t}
$$

where $A_{j}=-\bar{A}_{j} / j$ and $B_{j}=-\bar{B}_{j} / j$.

Four kinds of yields (3, 6, 12 and 60 months) are used in the estimation. Since the underlying model is a two-factor model, at least two kinds of the bond yields must be postulated to fit the model only with error. I assume that the yields of 3- and 60-month bonds are observed without error because they are more frequently traded than the other two kinds of bond on the U.S. Treasury bond market, and the 6- and 12-month bond yields are assumed to be measured with errors. Furthermore, I assume the measurement errors are serially uncorrelated, and are independent across the yields. Let $R_{t}=$ $\left(r_{3, t}, r_{60, t}, r_{6, t}, r_{12, t}\right)^{\prime}$, with $r_{3, t}$ and $r_{60, t}$ observed without errors. Stacking the corresponding $A_{j}$ and $B_{j}$ 's, I can then write

$$
R_{t}=A+B F_{t}+B^{m} u_{t}^{m}
$$

where $B^{m}$ is a $4 \times 4$ diagonal matrix with zero's as the first two diagonal elements and the standard deviations of the measurement errors as the remaining two diagonal elements . $u_{t}^{m}$ is a four-dimensional Gaussian white noise with an identity covariance matrix. I assume $u_{t}^{m}$ is independent with $F_{t}$.

Equation (2.1) and (2.13) form a Kalman filtering model, with (2.1) as the "state" or "plant" equation and (2.13) the "observation" equation. The 
Kalman filter is constructed through a recursive structure that can be briefly described as follows: assume the distribution of $F_{t}$ conditional on the information set at $t-1$ is

$$
F_{t \mid t-1} \sim N\left(\bar{F}_{t \mid t-1}, \Omega_{t \mid t-1}\right),
$$

then the distribution of $R_{t}$ conditional on the information set at $t-1$ is

$$
R_{t \mid t-1} \sim N\left(A+B \bar{F}_{t \mid t-1}, B \Omega_{t \mid t-1} B^{\prime}+B^{m} B^{m^{\prime}}\right)
$$

Having observed the value of $R_{t}$, one can update the inference about the state $F_{t}$ as

$$
F_{t \mid t} \sim N\left(\bar{F}_{t \mid t}, \Omega_{t \mid t}\right)
$$

where

$$
\begin{aligned}
& \bar{F}_{t \mid t}=\bar{F}_{t \mid t-1}+\Omega_{t \mid t-1} B^{\prime}\left(B \Omega_{t \mid t-1} B^{\prime}+B^{m} B^{m^{\prime}}\right)^{-1}\left(R_{t}-A-B \bar{F}_{t \mid t-1}\right) \\
& \Omega_{t \mid t}=\Omega_{t \mid t-1}-\Omega_{t \mid t-1} B^{\prime}\left(B \Omega_{t \mid t-1} B^{\prime}+B^{m} B^{m^{\prime}}\right)^{-1} B \Omega_{t \mid t-1}
\end{aligned}
$$

and the distribution of $F_{t+1}$ conditional on the information set at $t$ is

$$
F_{t+1 \mid t} \sim N\left(\bar{F}_{t+1 \mid t}, \Omega_{t+1 \mid t}\right),
$$

where

$$
\begin{aligned}
& \bar{F}_{t+1 \mid t}=\mu_{F}+\Psi_{F} \bar{F}_{t \mid t} \\
& \Omega_{t+1 \mid t}=\Psi_{F} \Omega_{t \mid t} \Psi_{F}^{\prime}+\Sigma_{F} \Sigma_{F}^{\prime}
\end{aligned}
$$

Therefore, the conditional p.d.f. of $R_{t} \mid R_{t-1}$ can be recursively constructed as follows:

$$
\begin{aligned}
f_{R_{r} \mid R_{t-1}}\left(R_{t} \mid R_{t-1}\right)= & (2 \pi)^{-N / 2}\left|B \Omega_{t \mid t-1} B^{\prime}+B^{m} B^{m^{\prime}}\right|^{-1 / 2} \\
& \times \exp \left\{-\frac{1}{2}\left(R_{t}-A-B \bar{F}_{t \mid t-1}\right)^{\prime}\left(B \Omega_{t \mid t-1} B^{\prime}+B^{m} B^{m^{\prime}}\right)^{-1}\right. \\
& \left.\times\left(R_{t}-A-B \bar{F}_{t \mid t-1}\right)\right\}
\end{aligned}
$$

for $t=2, \ldots, T$. 
From (2.19) it is a simple matter to construct the sample log-likelihood function

$$
\log (L(\theta))=\sum_{t=2}^{T} \log f_{R_{t} \mid R_{t-1}}\left(R_{t} \mid R_{t-1}\right)+\log f\left(R_{1}\right)
$$

where $\theta=\left(A\left(\mu_{F}, \Psi_{F}, \Sigma_{F}, \delta_{0}, \delta_{1}\right), B\left(\mu_{F}, \Psi_{F}, \Sigma_{F}, \delta_{0}, \delta_{1}\right), B^{m}\right) . \quad f\left(R_{1}\right)$ is the unconditional density function for $R_{1}$, which has a normal distribution:

$R_{1} \sim N\left(A+B\left(I-\Psi_{F}\right)^{-1} \mu_{F}, B\left(I-\Psi_{F}\right)^{-1} \Sigma_{F} \Sigma_{F}^{\prime}\left(\left(I-\Psi_{F}\right)^{-1}\right)^{\prime} B^{\prime}+B^{m} B^{m^{\prime}}\right)$

Dai and Singleton (1999) discuss the identification problem of such latentfactor model estimations in detail. In order to eliminate the observational equivalences resulting from non-singular rotations, $\mu_{F}$ in (2.1) is assumed to be a zero vector, and $\Psi_{F}$ a lower triangular matrix. I further restrict $\Psi_{F}$ as diagonal so that $F_{t}$ 's are independent with each other. This restriction is made to keep conformity with the usual empirical estimation studies, many of which adopt the assumption of independence among the latent factors, like Longstaff and Schwartz (1992) and Chen and Scott (1993). Furthermore, to eliminate the equivalences from unitary rotations, I normalize $\Sigma_{F}$ to be an identity matrix. Thus equation (2.1) becomes

$$
\begin{aligned}
F_{t} & =\rho F_{t-1}+u_{t} \\
r_{t} & =\delta_{0}+\delta_{1}^{\prime} F_{t}
\end{aligned}
$$

And finally the log likelihood in equation (2.20) is maximized to estimate the parameters $\theta=\left(A\left(\rho, \delta_{0}, \delta_{1}\right), B\left(\rho, \delta_{0}, \delta_{1}\right), B^{m}\left(\sigma_{6}, \sigma_{12}\right)\right)$.

\section{Monetary-policy Innovations Estimations}

To investigate how the term structure reacts to the structural changes in the macro economy over time, we need to specify the changes themselves in the first place - here the monetary-policy innovations or "surprises" pertain. However, such innovations or surprises are not directly observable. Each movement of the Federal Open Market Committee (FOMC) can be decomposed into two parts: the part that has been expected by the public, and the part that surprises the public. It is the latter part that drives the movement 
of the yield curve in response to the Federal Reserve announcements. Therefore, how to separate the latter part from the "expected part" of the policy announcements is in question.

There is no consensus among the monetary economists on how the public forms expectation on Federal Reserve policy. Vector Autoregression (VAR) estimation models are widely used to decompose the variations of macro variables into policy and non-policy components. On the other hand, following Taylor (1993), there has been a large literature trying to estimate a federal funds rate response function ("Taylor rule") as the Federal Reserve's policy rule. To make my results more robust, I adopt both identification strategies.

\subsection{A Six-variable Identified VAR Model}

In one of my earlier papers (Wu (2001b)) I use a recursive strategy to identify the monetary-policy innovations and other kinds of macro shocks. I establish the following identified VAR model and examine the impulse responses of the U.S. economy to structural innovations in the macro economy:

$$
a Y_{t}=A(L) Y_{t-1}+\Sigma \varepsilon_{Y, t}
$$

The data vector of the macro variables is given by $Y_{t} \equiv(I P, E M, P C E$, $\left.M_{1}, F F, P C O M\right)^{\prime}$, where IP denotes the logarithm of industrial production; $\mathrm{EM}$ is the logarithm of nonagricultural payroll employment in private sector; PCE represents the logarithm of the personal consumption expenditures price index; M1 refers to the logarithm of the monetary aggregate M1; FF is the federal funds rate, and PCOM represents the logarithm of spot market price index for all commodities.

$\mathrm{Wu}(2001 \mathrm{~b})$ assumes that the price level and real economic activity respond to monetary policy with a one-month lag, except for the commodity prices, which are formed in auction markets, and therefore can respond to any news contemporaneously. On the other hand, the monetary authority is only able to observe the price level and real economic activity with a one-month delay. This is because the measures of the price level and of real economic activity are compiled from survey data, which takes time to collect and are available to the monetary authority only with a delay. In accordance with these structural assumptions, in equation (3.1) $a$ is a lower-triangular square matrix: 


$$
a=\left[\begin{array}{cccccc}
1 & 0 & 0 & 0 & 0 & 0 \\
a_{21} & 1 & 0 & 0 & 0 & 0 \\
a_{31} & a_{32} & 1 & 0 & 0 & 0 \\
a_{41} & a_{42} & a_{43} & 1 & 0 & 0 \\
0 & 0 & 0 & a_{54} & 1 & 0 \\
a_{61} & a_{62} & a_{63} & a_{64} & a_{65} & 1
\end{array}\right]
$$

Note that in the fifth row, the first three elements are zeros, reflecting the fact that the monetary authority is not able to observe the current month's industrial productions, employment and the price level for consumption goods. $A(L)$ is a matrix polynomial in the lag operator $L$, and $\Sigma$ is a diagonal matrix.

I assume that the monetary authority uses the federal funds rate $F F$ as its policy instrument. Therefore, the fifth equation of the VAR system becomes the monetary policy reaction function:

$$
F F_{t}=A_{5}(L) Y_{t-1}-a_{54} M_{1, t}+\sigma_{55} \varepsilon_{F F, t}
$$

where $A_{5}(L)$ is the fifth row of the matrix polynomial $A(L)$, and $\sigma_{55}$ is the fifth diagonal element of the matrix $\Sigma$. The monetary-policy shock $\varepsilon_{F F, t}$ is the fifth element of $\varepsilon_{Y, t}$ and is assumed to be orthogonal to all other righthand-side variables in (3.1).

Equation (3.1) is estimated over the sample period 1983:01 to 1998:12. Twelve lagged values are estimated in each equation, with the initial lags beginning in 1982:01. $\widehat{\varepsilon_{F F}, t}$ 's are then calculated for each month and are used as proxies of the Federal Reserve policy "surprises" during the sample period.

\subsection{A GMM Estimation Model of the "Taylor Rule"}

Taylor (1993) advocates using one simple interest-rate response function instead of a system of equations like the one in (3.1) to describe the monetary

policy rule. The federal funds rate is assumed to respond to the inflation and the output gaps in the economy:

$$
r_{t}^{*}=\alpha^{*}+\beta \tilde{\pi}_{t}+\gamma \widetilde{y}_{t}
$$


where $r_{t}^{*}$ is the target level of the nominal federal funds rate in period $t . \tilde{\pi}_{t}$ is the inflation gap and $\widetilde{y}_{t}$ is the real output gap in the economy. $\alpha^{*}$ is, by construction, the desired nominal federal funds rate when both inflation and output are at their target levels.

Following Clarida, Gali and Gertler (1998), I define the inflation and output gaps as the gaps between the expected inflation and output levels and their respective target levels. Thus equation (3.3) becomes

$$
r_{t}^{*}=\alpha^{*}+\beta\left(E\left[\pi_{t, k} \mid \Omega_{t}\right]-\pi^{*}\right)+\gamma E\left[x_{t, q} \mid \Omega_{t}\right]
$$

where $\pi_{t, k}$ denotes the percent change in the price level from periods $t$ to $t+k$ (expressed in annual rates). $\pi^{*}$ is the Federal Reserve's target level of inflation. $x_{t, q}$ is a measure of the average output gap between period $t$ and $t+q$, where the output gap is defined as the percent deviation of the actual GDP from the corresponding Federal Reserve's target level. $E$ is the expectational operator, and $\Omega_{t}$ is the information set at the time when the federal funds rate is set.

Equation (3.4) assumes immediate adjustment of the actual federal funds rate once its target level changes, and thus ignores the Federal Reserve's tendency to smooth changes in interest rates. ${ }^{1}$ Moreover, it assumes that the Federal Reserve has perfect control over the interest rates all the time, which is not what happens in reality.

An extension of (3.4) allows those assumptions to be relaxed. In particular, I specify the following $\mathrm{AR}(3)$ model for the actual monthly federal funds rate, $r_{t}$ :

$$
r_{t}=\left(1-\rho_{1}-\rho_{2}-\rho_{3}\right) r_{t}^{*}+\rho_{1} r_{t-1}+\rho_{2} r_{t-2}+\rho_{3} r_{t-3}+\varepsilon_{F F, t}
$$

where $\varepsilon_{F F, t}$ is a zero-mean exogenous monetary-policy shock, and $r_{t}^{*}$ is given by $(3.4)$.

Combining the partial adjustment equation (3.5) with the target model (3.4) yields the federal funds rate equation:

$$
r_{t}=\left(1-\rho_{1}-\rho_{2}-\rho_{3}\right)\left(\alpha+\beta \pi_{t, k}+\gamma x_{t, q}\right)+\rho_{1} r_{t-1}+\rho_{2} r_{t-2}+\rho_{3} r_{t-3}+v_{t}
$$

\footnotetext{
${ }^{1}$ See Rudebusch (1995) for evidence on the serial correlation of interest rate changes. Literature provides a number of explanations for this interest-rate smoothing behavior, including fear of disruption of financial market (Goodfriend (1991)), and uncertainty about the effects of interest rate changes (sack (1997)).
} 
where $\alpha \equiv \alpha^{*}-\beta \pi^{*}$ and $v_{t} \equiv-\left(1-\rho_{1}-\rho_{2}-\rho_{3}\right)\left\{\beta\left(\pi_{t, k}-E\left[\pi_{t, k} \mid \Omega_{t}\right]\right)+\gamma\left(x_{t, q}-\right.\right.$ $\left.\left.E\left[x_{t, q} \mid \Omega_{t}\right]\right)\right\}+\varepsilon_{F F, t}$. Note that $\left(\pi_{t, k}-E\left[\pi_{t, k} \mid \Omega_{t}\right]\right)$ and $\left(x_{t, q}-E\left[x_{t, q} \mid \Omega_{t}\right]\right)$ are forecasting errors and are thus orthogonal to any variable in the information set $\Omega_{t}$.

Let $z_{t}$ be a vector of instruments known when $r_{t}$ is set, which is orthogonal to the exogenous monetary shock $\varepsilon_{F F, t}$. Thus I have the set of orthogonality conditions:

$$
E\left\{v_{t} z_{t}\right\}=0
$$

with $v_{t}$ derived from (3.6):

$$
v_{t}=r_{t}-\left(1-\rho_{1}-\rho_{2}-\rho_{3}\right)\left(\alpha+\beta \pi_{t, k}+\gamma x_{t, q}\right)-\rho_{1} r_{t-1}-\rho_{2} r_{t-2}-\rho_{3} r_{t-3}
$$

Equation (3.7) provides the basis for the estimation of the parameter vector $\left(\alpha, \beta, \gamma, \rho_{1}, \rho_{2}, \rho_{3}\right)^{\prime}$, using the Generalized Method of Moments (Hansen (1982)), with an optimal weighting matrix that accounts for possible correlation across elements of $v_{t} z_{t}$. After the parameters are estimated, $\pi_{t, k}$ and $x_{t, q}$ are projected by OLS on the instrumental variables $z_{t}$ 's and the fitted values are used to formulate the expected inflation and GDP gaps, $E\left[\pi_{t, k} \mid \Omega_{t}\right]$ and $E\left[x_{t, q} \mid \Omega_{t}\right]$. Finally $\widehat{\varepsilon_{F F, t}}$ 's are computed for the whole sample period as

$\widehat{\varepsilon F F, t}=r_{t}-\left(1-\widehat{\rho_{1}}-\widehat{\rho_{2}}-\widehat{\rho_{3}}\right)\left(\widehat{\alpha}+\widehat{\beta} E\left[\pi_{t, k} \mid \Omega_{t}\right]+\widehat{\gamma} E\left[x_{t, q} \mid \Omega_{t}\right]\right)-\widehat{\rho_{1}} r_{t-1}-\widehat{\rho_{2}} r_{t-2}-\widehat{\rho_{3}} r_{t-3}$

and are used as proxies of the monetary-policy shocks.

In the GMM estimation I set $k=12$ and $q=6$. That is, I assume that the Federal Reserve Board is trying to control the inflation rate over the next twelve months and the output growth over the next six months at their respective target levels. This choice of policy horizons is consistent with the Federal Reserve Board's statements, and is also the horizons that Clarida, Gali and Gertler (1998) choose. The inflation measure is the annualized rate of change of the GDP deflator between two subsequent months. The output gap is constructed as the deviation of the logarithm of real GDP from a fitted cubic function of time. The instrumental variables in $z_{t}$ include current and twelve lags of the federal funds rate, inflation and output gap, as well as the current and twelve lags of commodity price inflation, M2 growth, and the spread between long-term bond rate and 3-month Treasury Bill rate from CITIBASE. 


\section{Data}

In estimating the term structure model I use data on nominal zero-coupon bond yields of maturities 3, 6, 12 and 60 months, covering the period from January 1983 to December 1998. The long-term bond yields (12, 60 months) are taken from Fama CRSP zero-coupon bond files, and the shorter maturity rates (3, 6 months) are taken from Fama CRSP Treasury Bill files.

The macro variables I use to construct the VAR model are: IP (logarithm of industrial production), EM (logarithm of nonagricultural payroll employment in private sector), PCE (logarithm of the personal consumption expenditures), M1 (logarithm of the monetary aggregate M1), FF (the federal funds rate), and PCOM (logarithm of spot market price index for all commodities) covering the period from January 1982 to December 1998 (including the initial twelve-month lags). All macro data are taken from CITIBASE, and are seasonally adjusted except for FF and PCOM.

The macro variables I use in the GMM estimation of the "Taylor rule" include: federal funds rate (FYFF), GDP deflator (GDPP), real GDP (GDPQ), Commodity price index (PSCCOM), M2, long-term bond rate (FYGL) and the 3-month Treasury Bill rate (FYGM3) from CITIBASE, covering the period from January 1982 to December 1998 (including the initial twelve-month lags).

\section{$5 \quad$ Estimation and Regression Results}

Table 1 reports the MLE estimates of the parameters $\rho, \delta_{0}$ and $\delta_{1}$ of the twolatent-factor term structure model. All the parameter estimates are statistically significant. Consistent with the results in previous multi-factor studies such as Chen and Scott (1993), Dai and Singleton (1999) and Babbs and Nowman (1999), there are a persistent "level factor" and a mean-reverting "slope factor". The estimate of $\rho_{1}$ is 0.9986 . This implies a mean half life of approximately 41 years, and corresponds to extremely slow mean reversion for the first factor. From the factor loadings (Figure 1) it can be seen that one unit of shock from this factor will change the bond yields across all maturities in almost the same magnitude. In other words, it will have a "level" effect on the yield curve. The estimate of $\rho_{2}$ is 0.9306 , implying a mean half life of 10 months. One unit of shock from this factor will have a larger effect on the short-term bond yields than on long-term bond yields, and will change 
the slope of the yield curve, which justifies the name it is given-slope factor. Finally, 3-month and 5-year bond yields are used to compute the time series of the unobservable level and slope factors during the sample period.

Figure 2 displays the impulse responses of the macro variables to different structural shocks from the macro economy. Bayesian Monte Carlo methods are used to compute $68 \%$ confidence bands. The confidence bands are displayed around the point estimates of the impulse responses ${ }^{2}$. Both the impulse responses and the confidence bands are measured in percentage deviation from the non-stochastic steady state. Our particular interest is in the fifth row of the graphs, which corresponds to the equation for federal funds rate $F F_{t}$ in (3.1). The estimation residual $\widehat{\varepsilon_{F F}, t}$ 's are calculated in each month and used as a proxy of the Federal Reserve policy "surprises".

The GMM estimates of the parameters of the "Taylor rule" are reported in Table 2. Standard errors are shown in brackets and the last row reports the $\chi^{2}$ statistics for testing the model's over-identifying restrictions. The estimation results show that most of the parameter estimates are statistically significant (with the exceptions of $\widehat{\alpha}$ and $\widehat{\gamma}$ ), and the model is not rejected at conventional significance levels. Noticeably, the estimate of $\beta$, the coefficient associated with expected inflation, is greater than one during the sample period (after 1982). This is consistent with the results of other similar studies of the inflation-control practice under Volcker-Greenspan administration. The residual $\widehat{\varepsilon_{F F}, t}$ 's are calculated following the steps described in Section 3 (equation 3.8) and are used to mimic the exogenous monetary-policy shocks.

The $\widehat{\varepsilon_{F F},}$ 's computed from VAR model has a standard deviation of 0.1705 , while it is 0.3075 for the $\widehat{\varepsilon_{F F}, t}$ 's calculated from GMM model. Figure 3 compares these two series of $\widehat{\varepsilon_{F F},}$ 's after normalizing them with unity standard deviations. The top panel of the figure graphs the time series plot of the two series: in many months of the sample period the two series are similar to each other, both in signs and in magnitudes, although in some of the months they are significantly different (for example, around 1983:01, 1991:02 and 1995:11). The bottom panel of Figure 3 draws the scatter diagram of

${ }^{2}$ The fifth column of Figure 2 shows little effect of a monetary-policy shock on the industrial production, $\mathrm{PCE}$ index or employment, while the economic intuition is that such a shock would have contractionary effects on these variables. One interpretation of this might be that during the sample period (after 1982), the magnitudes of monetarypolicy shocks are small, therefore there is not enough variation to get sharp estimates of responses for those variables, although the contractionary response patterns are still contained in the error bands. 
one series against the other. Most of the points gather around the $45^{\circ}$ line, suggesting a strong correlation: the computed correlation coefficient between them is 0.5761 .

Having extracted the slope factor as well as the exogenous monetarypolicy shocks during the sample period, I go on to explore the relation between them. I regress the monetary-policy shocks on the yields of 3-month and 5-year bonds, and construct a portfolio mimicking the monetary-policy shocks, with the regression coefficients as the weights attached to each of the bonds in the portfolio. The correlations of the monthly returns on this "monetary-policy mimicking" portfolio with the two latent factors (each of which is also computed from its respective mimicking portfolio composed of 3 -month and 5-year bonds) are reported in Table 3. Column 2 of the table shows the correlations where the monetary-policy shocks are estimated from the VAR model, and column 3 reports the results where the monetary-policy shocks are estimated from the GMM estimation of the "Taylor rule". The correlation coefficient between the level factor and the return on "monetarypolicy mimicking" portfolio where the monetary-policy shocks are estimated from the VAR model is 0.1127 and is 0.8390 between the slope factor and the return on "monetary-policy shock mimicking" portfolio. Using the GMM estimation results the correlation coefficients are 0.3632 between the level factor and the return on "monetary-policy mimicking" portfolio, and 0.6718 between the slope factor and the return on "monetary-policy mimicking" portfolio. Both sets of results show that the monetary-policy shocks are much more strongly correlated with the slope factor than with the level factor. In other words, the monetary policy affect the nominal term structure mainly through its influences on the slope factor.

Next I examine to what extent the monetary-policy shocks drive the movement of the slope factor. I regress the innovations to the level and slope factors on a constant and contemporaneous and lagged returns on the "monetary policy mimicking" portfolio. The innovations to the factors are constructed through (2.21) as

$$
\widehat{u_{t}}=\bar{F}_{t \mid T}-\widehat{\rho} \bar{F}_{t-1 \mid T}
$$

where $\bar{F}_{t \mid T} \equiv E\left\{F_{t} \mid R_{1}, R_{2}, \ldots, R_{T}\right\}$ are the latent factors, and the regression equation is

$$
\widehat{u_{t}}=a+X_{t} b+\zeta_{t}
$$


where $X_{t}$ is the contemporaneous and lagged "monetary policy mimicking" portfolio return $\left(R_{m p, t}, R_{m p, t-1}, R_{m p, t-2}, \ldots, R_{m p, t-6}\right)^{\prime}$ and $\zeta_{t}$ is the regression error.

The regression results are displayed in Table 4. The second column reports the regression results where the monetary-policy shocks are estimated from the VAR model, and the third column reports the results where the monetary-policy shocks are estimated from the GMM model. The estimated standard deviations are reported in the parentheses. All of the estimated coefficients in the first three rows of Table 4 are significantly different from zeros at the $5 \%$ significance level, indicating that the monetary-policy innovations have significant influence on both factors. In particular, in the regressions of the changes in slope factor on the contemporaneous and lagged returns on the "monetary policy mimicking" portfolio, the coefficients of the contemporaneous monetary-policy shock are 33.6008 for VAR and 62.9966 for GMM, with a $t$-ratio of 52.96 and 9.54 accordingly. The adjusted $R^{2}$ is 0.9142 for the regression where the monetary-policy shocks are estimated from the VAR model, and 0.7843 for the regression where the monetary-policy shocks are estimated from the GMM estimation. That is, monetary-policy innovations account for a large part of the variability of the estimated "slope" factor. The adjusted $R^{2}$ are only 0.3173 and 0.1552 for the regressions of the innovations to level factor on monetary-policy shocks from the VAR and GMM estimations respectively, suggesting that monetary-policy innovations account for much less variability of the "level" factor.

$\mathrm{Wu}$ (2001a) establishes a general-equilibrium based term structure model, in which the one-period interest rate is determined by a monetary policy rule aiming at actively controlling the inflation. The results of his simulation study shows that most of variability of the slope factor is driven by exogenous monetary-policy shocks, while the same shocks can only explain a much less part of variability of the level factor. The fact that the results reported in Table 4 match those obtained from $\mathrm{Wu}$ (2001a) is evidence for the effects of monetary policy predicted by his theoretical model: a monetary contraction generates high nominal short-term interest rates, but because of the antiinflationary effects of the contraction, the interest rates will be lowered later. With such an expectation of the movement of future short-term interest rates, the current long-term interest rates decrease, and as a result the slope of the yield curve declines as the contractionary monetary-policy shocks occur. 


\section{Concluding Remarks}

In this paper I examine the empirical relationship between the movement of the slope factor in the term structure of nominal interest rates and monetary policy shocks in the U.S. since 1982. I estimate a two-latent-factor term structure model and extract the underlying slope factor. Meanwhile, I establish a six-variable VAR model as well as a GMM estimation model of the "Taylor rule" to estimate the exogenous monetary-policy shocks in the U.S. during the same period. The subsequent correlation and regression studies suggest that there is strong correlation between the slope factor and exogenous monetary-policy shocks. Moreover, monetary-policy shocks can explain a large part of variability of the slope factor. This study provides strong evidence in support of Knez, Litterman and Scheinkman (1994)'s conjecture on the relation between the slope factor and the Federal Reserve policy, and is also consistent with the results in Wu (2001a)'s general-equilibrium based simulation study. 


\section{References}

[1] Ang, Andrew and M. Piazzesi, 1999. "A No-Arbitrage Vector Autoregression of Term Structure Dynamics with Macroeconomic and Latent Variables", working paper, Columbia University.

[2] Babbs, S. H., and K. B. Nowman, 1999. "Kalman Filtering of Generalized Vasicek Term Structure Models", Journal of Financial and Quantitative Analysis, 34 (1), 115-130.

[3] Chen, R. R., and L. Scott, 1993. "Maximum Likelihood Estimation for a Multifactor Equilibrium Model of the Term Structure of Interest Rates", Journal of Fixed Income, 3, September, 14-31.

[4] Clarida, Richard, J. Gali and M. Gertler, 1998. "Monetary Policy Rules And Macroeconomic Stability: Evidence and Some Theory", NBER Working Paper 6442.

[5] Cox, J. C., J. E. Ingersoll, and S. A. Ross, 1981. "A Reexamination of Traditional Hypotheses about the term structure of interest rates", Journal of Finance, 36, 769-799.

[6] —, J. E. Ingersoll, and S. A. Ross, 1985a, "An Intertemporal General Equilibrium Model of Asset Prices", Econometrica, 53, 363-384.

[7] —, J. E. Ingersoll, and S. A. Ross, 1985b, "A theory of the term structure of interest rates", Econometrica, 53, 385-407.

[8] Dai, Q., and K. Singleton, 1999. "Specification Analysis of Affine Term Structure Models", Journal of Finance, to appear.

[9] Duffie, Darrell and R. Kan, 1995. "A Yield-Factor Model of Interest Rates", working paper, Graduate School of Business, Stanford University.

[10] Evans C. L. and D. A. Marshall, 1998. "Monetary Policy and the Term Structure of Nominal Interest Rates: Evidence and Theory", CarnegieRochester Conference Series on Public Policy, 49, 53-111.

[11] Goodfriend, Marvin (1991). "Interest Rates and the Conduct of Monetary Policy", Carnegie-Rochester Conference Series on Public Policy, 34, 7-30. 
[12] Hamilton, J. D., 1994. Time Series Analysis, Princeton University Press.

[13] Hansen, Lars (1982). "Large Sample Properties of Generalized Method of Moments Estimators", Econometrica, 50, 1029-1054.

[14] Harrison, J. M., and D. M. Kreps, 1979. "Martingales and Arbitrage in Multiperiod Securities Markets", Journal of Economic Theory, 2 (3), 381-408.

[15] Knez, P., Litterman, R., and J. A. Scheinkman, 1994. "Explorations into Factors Explaining Money Market Returns", Journal of Finance, 49, 1861-1882.

[16] Litterman, R., and J. A. Scheinkman, J., 1991. "Common Factors Affecting Bond Returns", Journal of Fixed Income, 1, 54-61.

[17] Longstaff, F.A. and E.S. Schwartz, 1992. "Interest Rate Volatility and the Term Structure: A Two Factor General Equilibrium Model", Journal of Finance, 47 (4), 1252-1282.

[18] Piazzesi, Monika, 1999. "An Econometric Model of the Yield Curve with Macroeconomic Jump Effects", Ph.D. dissertation, Stanford University.

[19] Rudebusch, Glenn (1995). "Federal Reserve Interest Rate Targeting, Rational Expectations, and the Term Structure", Journal of Monetary Economics, 35, 245-274.

[20] Sack, Brian (1997). "Uncertainty and Gradual Monetary Policy", Federal Reserve Board, mimeo.

[21] Vasicek, O., 1977, "An Equilibrium Characterization of the Term Structure", Journal of Financial Economics, 5, 177-188.

[22] Wu, Tao, 2001a, "Macro Factors and the Affine Term Structure of Interest Rates", Ph.D. dissertation, Yale University, 2001.

[23] —, 2001b, "Stylized Facts on Nominal Term Structure and Business Cycles: An Empirical VAR study", manuscript, 2001. 


\section{Table 1: Term Structure Model Estimates}

\begin{tabular}{|c|c|c|c|c|c|}
\hline \multicolumn{6}{|c|}{ Short Rate Parameters } \\
\hline \multirow[t]{2}{*}{$\widehat{\delta_{0}}$} & 0.5472 & $\widehat{\delta_{1}}$ & 0.0043 & $\widehat{\delta_{2}}$ & 0.0044 \\
\hline & $(0.0532)$ & & $(0.0020)$ & & $(0.0002)$ \\
\hline \multicolumn{6}{|c|}{ Latent Factor Parameters } \\
\hline & 0.9986 & $\widehat{\rho_{2}}$ & 0.9306 & & \\
\hline & $(0.0001)$ & & $(0.0047)$ & & \\
\hline \multicolumn{6}{|c|}{ 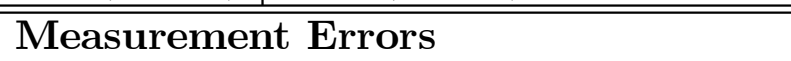 } \\
\hline \multirow[t]{2}{*}{$\widehat{\sigma_{6}}$} & 0.0016 & $\widehat{\sigma_{12}}$ & 0.0025 & & \\
\hline & $(0.0001)$ & & $(0.0001)$ & & \\
\hline
\end{tabular}

Note: Table 1 displays the MLE estimation results of the latent-factor model using the term structure data from the CRSP data set. The sample period is from 1983:01 to 1998:12. The standard deviations of the parameter estimates are reported in the parentheses. The 6-month and 12-month bond yields are assumed to be measured with errors. 


\section{Table 2: GMM Estimation Results of the "Taylor Rule"}

\begin{tabular}{cccccc}
\hline$\widehat{\alpha}$ & $\widehat{\beta}$ & $\widehat{\gamma}$ & $\widehat{\rho_{1}}$ & $\widehat{\rho_{2}}$ & $\widehat{\rho_{3}}$ \\
\hline 0.09 & 1.62 & 0.26 & 0.77 & 0.17 & 0.06 \\
$(0.34)$ & $(0.21)$ & $(0.18)$ & $(0.07)$ & $(0.04)$ & $(0.01)$ \\
\hline$\chi^{2}(72):$ & 15.82 & & & &
\end{tabular}

Note: Table 2 displays the GMM estimation results of the "Taylor rule" (equation (3.5)) using the data from CITIBASE. The sample period is from 1983:01 to 1998:12, with the initial lags starting from 1982:01. The standard deviations of the parameter estimates are reported in the parentheses. $\chi^{2}$ statistics is formulated to test the model's overidentifying restrictions. 


\section{Table 3: Correlations Between the Latent Factors and the "Monetary Policy Mimicking" Portfolio}

\begin{tabular}{c|c|c}
\hline & VAR & GMM \\
\hline \hline "level" & 0.1127 & 0.3632 \\
\hline "slope" & 0.8390 & 0.6718 \\
\hline
\end{tabular}

Note: Table 3 displays the correlation coefficient between the latent factors and the returns on the portfolios mimicking the monetary-policy shocks. The first column reports the results using the exogenous monetary-policy shocks obtained from the VAR estimations, and the second column reports the results using the monetary-policy shocks obtained from the GMM estimation of the "Taylor rule". 
Table 4: Regression Results of Equation (5.2)

\begin{tabular}{l|ll|ll}
\hline & VAR & & GMM & \\
\hline \hline & $\widehat{u_{1, t}}($ innovations & $\widehat{u_{2, t}}$ (innovations & $\widehat{u_{1, t} \text { (innovations }}$ & $\widehat{u_{2, t} \text { (innovations }}$ \\
& to level factor) & to slope factor) & to level factor) & to slope factor) \\
\hline Constant & -0.2250 & -0.1949 & -0.1537 & -0.3488 \\
& $(0.0045)$ & $(0.0005)$ & $(0.0132)$ & $(0.0030)$ \\
$R_{m p, t}$ & -21.8777 & 33.6008 & -32.7762 & 62.9966 \\
& $(5.6746)$ & $(0.6344)$ & $(28.8643)$ & $(6.6030)$ \\
$R_{m p, t-1}$ & 22.3945 & -31.7462 & 34.0375 & -60.2365 \\
& $(13.3765)$ & $(1.4964)$ & $(70.0156)$ & $(16.0167)$ \\
$R_{m p, t-2}$ & -2.1646 & 0.6368 & -3.8390 & 1.6098 \\
& $(13.9637)$ & $(1.5610)$ & $(73.1072)$ & $(16.7239)$ \\
$R_{m p, t-3}$ & 0.4749 & -0.1671 & 1.2422 & -0.6496 \\
& $(14.0127)$ & $(1.5665)$ & $(72.4355)$ & $(16.5702)$ \\
$R_{m p, t-4}$ & -0.1143 & -0.0390 & -1.1740 & 0.3373 \\
& $(13.7225)$ & $(1.5341)$ & $(69.8248)$ & $(15.9730)$ \\
$R_{m p, t-5}$ & 3.5608 & -1.0641 & 7.2028 & -3.0341 \\
& $(13.1448)$ & $(1.4695)$ & $(66.4610)$ & $(15.2035)$ \\
$R_{m p, t-6}$ & -2.9627 & 0.6643 & -5.9917 & 1.8160 \\
& $(5.6413)$ & $(0.6307)$ & $(27.9588)$ & $(6.3958)$ \\
\hline \hline Adj. $R^{2}$ & 0.3173 & 0.9142 & 0.1552 & 0.7843
\end{tabular}

Note: Table 4 reports the regression results of equation (5.2): $\widehat{u_{t}}=a+X_{t} b+$ $\zeta_{t} . \widehat{u_{1, t}}$ and $\widehat{u_{2, t}}$ are innovations to the level and slope factors respectively. $X_{t}=$ $\left(R_{m p, t}, R_{m p, t-1}, \ldots, R_{m p, t-6}\right)^{\prime}$ where $R_{m p, t}$ is the return on "monetary policy mimicking" portfolio, and $\zeta_{t}$ is the regression error. Columns 2 and 3 report the estimates of $a$ and $b$, with monetary-policy shocks calculated from the VAR estimation. Columns 4 and 5 report the estimates of $a$ and $b$, with monetary-policy shocks calculated from the GMM estimation. 
Figure 1: Factor Loadings of the Term Structure Model

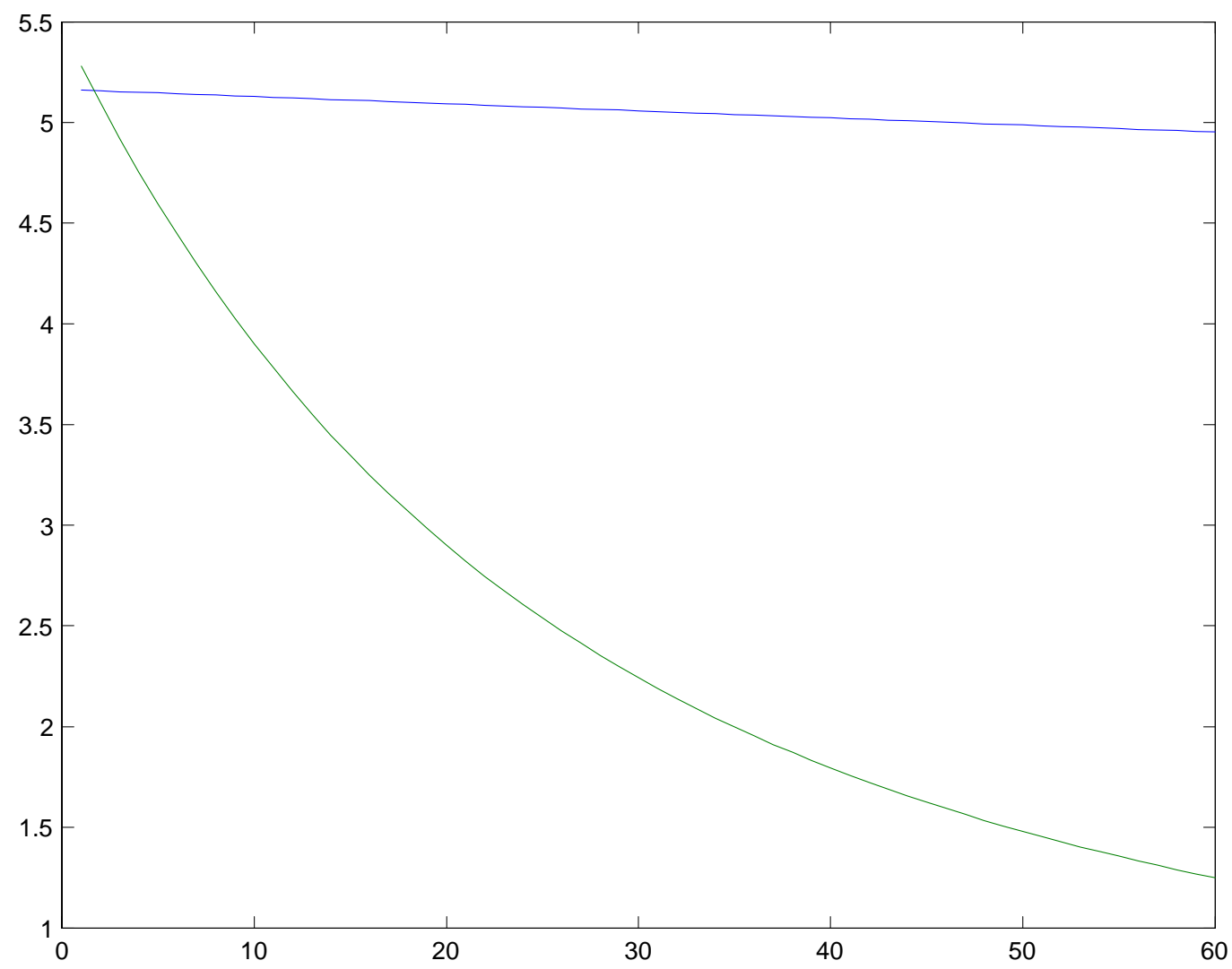

Note: Figure 1 displays the factor loadings from the estimation of a two-latent-factor model using the data on nominal bond yields from the CRSP data set. The yields of 3 , 6, 12 and 60-month nominal zero-coupon bonds are used in the estimation. The yields of 3 and 60-month bonds are used to invert the latent variables, and the yields of 6 and 12-month bonds are assumed to be measured with errors. The maturity of the bonds is on the $x$-axis in months, and the $y$-axis shows factor loadings in annualized percentage points. 
Figure 2: Impulse Responses from the VAR Estimation

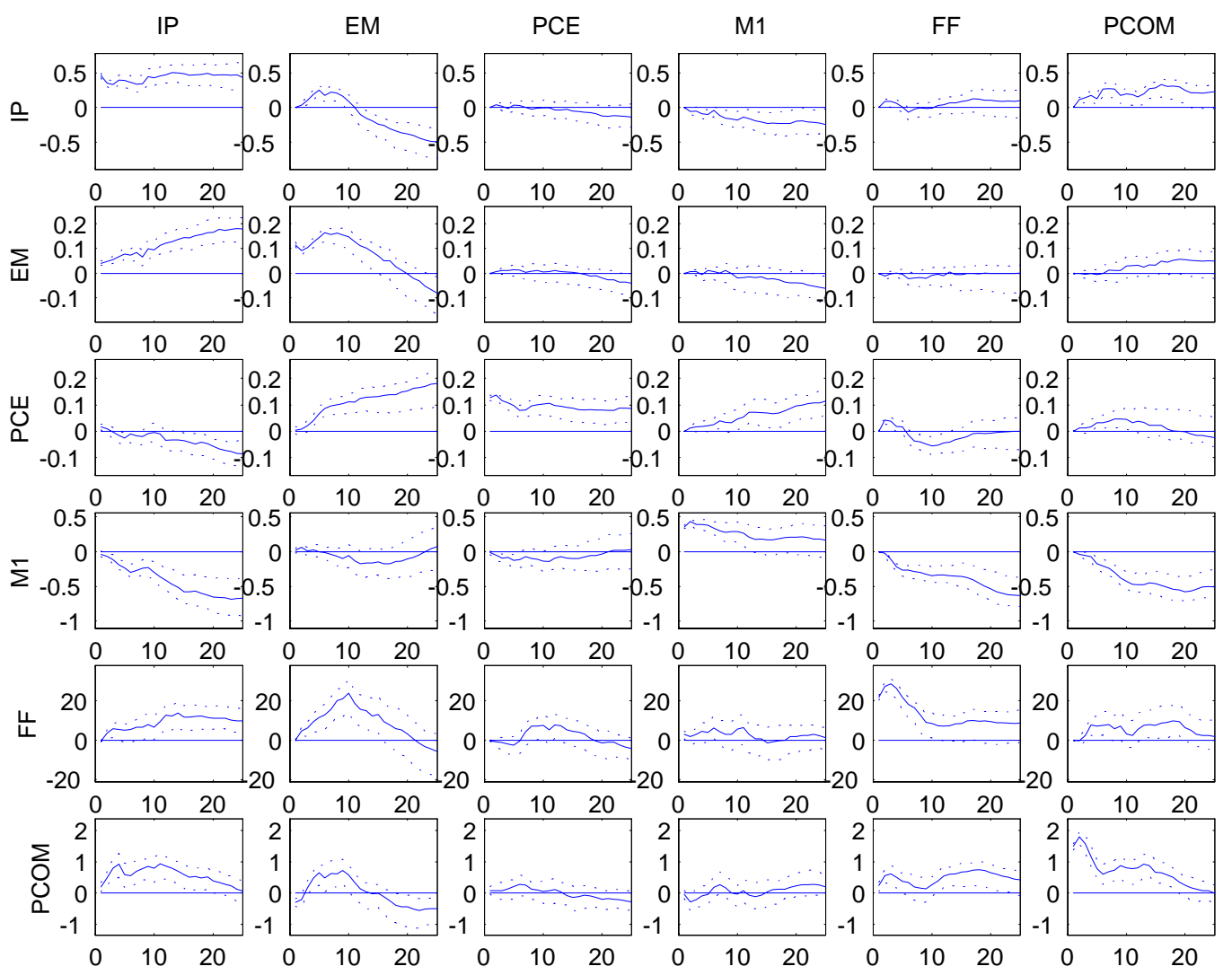

Note: Figure 2 displays the impulse responses of macro variables to one-standarddeviation macro shocks in the identified VAR study. IP, EM and PCE denote the logarithms of industrial production, nonagricultural payroll employment and the PCE deflator, respectively. M1 represents the logarithm of the monetary aggregate, FF is the federal funds rate, and PCOM stands for the smoothed change in index of sensitive materials prices. Data period is 1983:01-1998:12, with the initial lags starting from 1982:01. For IP, EM, PCE, M1 and PCOM, the impulse responses are in units of percentage deviations from the steady state. For the federal funds rate FF, the units are basis points per annum. The solid lines plot the point estimates for the impulse responses, and the dashdot lines give $68 \%$ confidence bands obtained from Bayesian Monte Carlo method. 
Figure 3: Graphs of the Monetary-policy Shocks

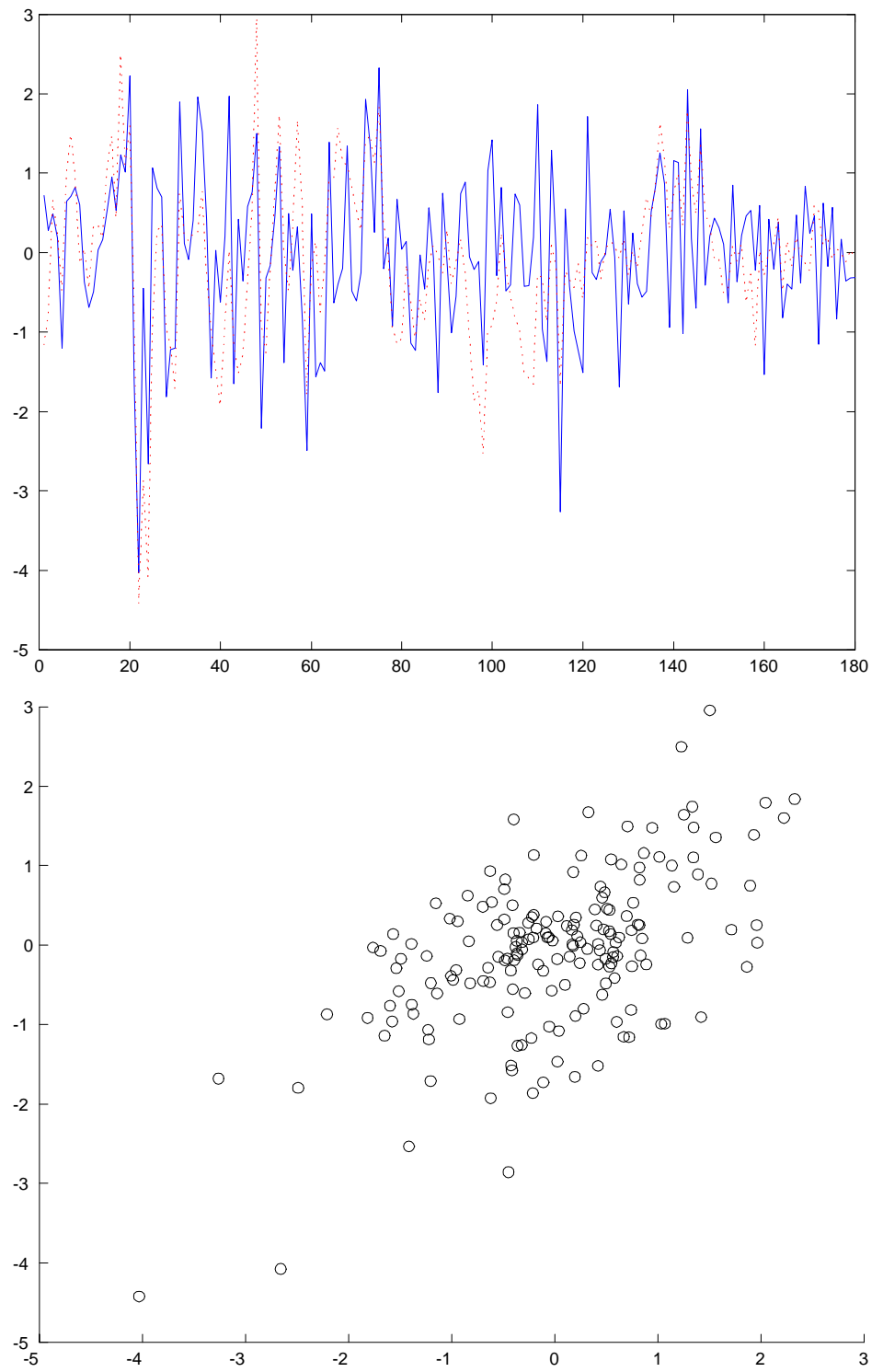

Note: The top panel of Figure 3 graphs the time series plot of the monetary-policy shocks $\widehat{\varepsilon_{F F}, t}$ 's computed from the VAR and GMM models (the solid line is the series from VAR estimation, and the dotted line is the series from GMM eestimation). The sample period is from 1983:01 to 1997:12 (180 months). The bottom panel draws the scatter diagram of one series against the other. Both series are normalized to unity standard deviations. The correlation coefficient between the two series is 0.5761 . 